\title{
Intracellular Detection of ATP Using an Aptamer Beacon Covalently Linked to Graphene Oxide Resisting Non-specific Probe Displacement
}

\author{
Zhenbao Liu ${ }^{\mathrm{a}}$, Shanshan Chen ${ }^{\mathrm{a}}$, Biwu Liu ${ }^{\mathrm{b}}$, Jianping $\mathrm{Wu}^{\mathrm{a}}$, Yanbin Zhou ${ }^{\mathrm{a}}$, Lingyun $\mathrm{He}^{\mathrm{a}}$, \\ Jinsong Ding ${ }^{\text {a.* }}$ and Juewen Liu ${ }^{\text {a.b.** }}$ \\ ${ }^{a}$ School of Pharmaceutical Sciences, Central South University, Changsha 410013, \\ Hunan, China \\ Email: dingjs0221@163.com \\ ${ }^{b}$ Department of Chemistry, Waterloo Institute for Nanotechnology, University of \\ Waterloo, Waterloo, Ontario, Canada, N2L 3G1 \\ Email: liujw@uwaterloo.ca
}

Fax: (519) 746-0435

This document is the Accepted Manuscript version of a Published Work that appeared in final form in Analytical Chemistry copyright (c) American Chemical Society after peer review and technical editing by publisher. To access the final edited and published work see Liu, Z., Chen, S., Liu, B., Wu, J., Zhou, Y., He, L., ... Liu, J. (2014). Intracellular Detection of ATP Using an Aptamer Beacon Covalently Linked to Graphene Oxide Resisting Nonspecific Probe Displacement. Analytical Chemistry, 86(24), 12229-12235. https://doi.org/10.1021/ac503358m 


\begin{abstract}
Fluorescent aptamer probes physisorbed on graphene oxide (GO) have recently emerged as a useful sensing platform. Signal is generated by analyte-induced probe desorption. To address non-specific probe displacement and false positive signal, we herein report a covalently linked aptamer probe for ATP detection. A fluorophore and amino dual-modified aptamer was linked to the carboxyl group on GO with a coupling efficiency of $\sim 50 \%$. The linearity, specificity, stability, and regeneration of the covalent sensor was systematically studied and compared to the physisorbed probe. Both sensors have similar sensitivity, but the covalent one is more resistant to non-specific probe displacement by proteins. The covalent sensor has a dynamic range from $0.125 \mathrm{mM}$ to 2 $\mathrm{mM}$ ATP in buffer at room temperature and is resistance to DNase I. Intracellular ATP imaging was demonstrated using the covalent sensor, which generated higher fluorescence signal than the physisorbed sensor. After stimulating the cells with $5 \mathrm{mM}$ $\mathrm{Ca}^{2+}$ for ATP production, the intracellular signal enhanced by $31.8 \%$. This work highlights the advantages of covalent aptamer sensors using GO as both a quencher and a delivery vehicle for intracellular metabolite detection.
\end{abstract}




\section{Introduction}

Graphene is a single layer of graphite with many unique physical and chemical properties. ${ }^{1,2}$ Since graphene has a large specific surface area and rich $\pi$ electrons, it adsorbs a diverse range of molecules. ${ }^{3}$ To disperse in aqueous solutions, graphene oxide (GO) with various surface hydroxyl, epoxy and carboxyl groups is often used. ${ }^{4}$ GO has emerged as an analytical platform in the past few years to interface with various biopolymers, especially with DNA. ${ }^{5-11}$ The success of this platform owes to the following three properties. First, GO is an efficient and general fluorescence quencher and all tested fluorophores are strongly quenched nearby the GO surface. ${ }^{12-15}$ Second, the affinity of DNA adsorption on GO is intermediate via $\pi-\pi$ stacking and hydrogen bonding. The binding is strong enough to allow a low background signal, while still weak enough to allow quick probe desorption in the presence of target molecules. ${ }^{16-19}$ For comparison, carbon nanotubes (CNTs) bind DNA much more strongly partially due to DNA wrapping around CNTs, ${ }^{20-22}$ rendering the release of probe DNA difficult. Finally, DNA recognizes not only complementary nucleic acids, but also many other molecules including metal ions, small molecules, proteins and even whole cells via the aptamer technology. ${ }^{23-28}$

In 2009, Yang and co-workers reported a sensing scheme shown in Figure $1 \mathrm{~A}^{5} \mathrm{~A}$ fluorophore-labeled DNA probe is physisorbed on GO with suppressed fluorescence. In the presence of its target molecule, the probe is desorbed forming a binding complex and giving strong fluorescence enhancement. Since then, this scheme has been adapted in many different systems for detecting a broad range of analytes. ${ }^{6,29-31}$

Being highly negatively charged, normally DNA probes cannot spontaneously enter 
cells. A cationic delivery vehicle or nanostructured DNA is required for intracellular detection. ${ }^{32-34}$ Since nano-sized GO is readily internalized by mammalian cells, GO-based sensors can be directly used for intracellular detection. ${ }^{35,}{ }^{36}$ Furthermore, GO protects adsorbed DNA from degradation by nucleases, ${ }^{37}$ which is also important for detection in biological fluids. Intracellular adenosine triphosphate (ATP) detection using aptamer/GO complexes have been demonstrated by a few groups. ${ }^{38-42}$

A potential problem of the physisorption system is that the adsorbed probe might be displaced by non-target molecules, thus producing false positive signals. This is particularly problematic for intracellular detection since a high concentration of proteins and nucleic acids exist in both the culture medium and in cells. To solve this problem, Tan and co-workers employed a reference probe as the internal standard, where semi-quantitative measurement was demonstrated. ${ }^{40}$ While the internal standard facilitates fluorescence quantification, the loss of probe by non-specific displacement can hardly be avoided. Herein, we propose a covalent linkage forming an aptamer beacon, ${ }^{43}$ and GO is the quencher. Since the probe DNA does not leave the GO surface upon target binding, the covalent sensor has the advantage of being re-generable. ${ }^{44,45}$ In this work, detection of ATP inside cells is demonstrated. ATP is the main energy carrier, playing a critical role in cellular physiological processes and biochemical reactions. ${ }^{46}$ 

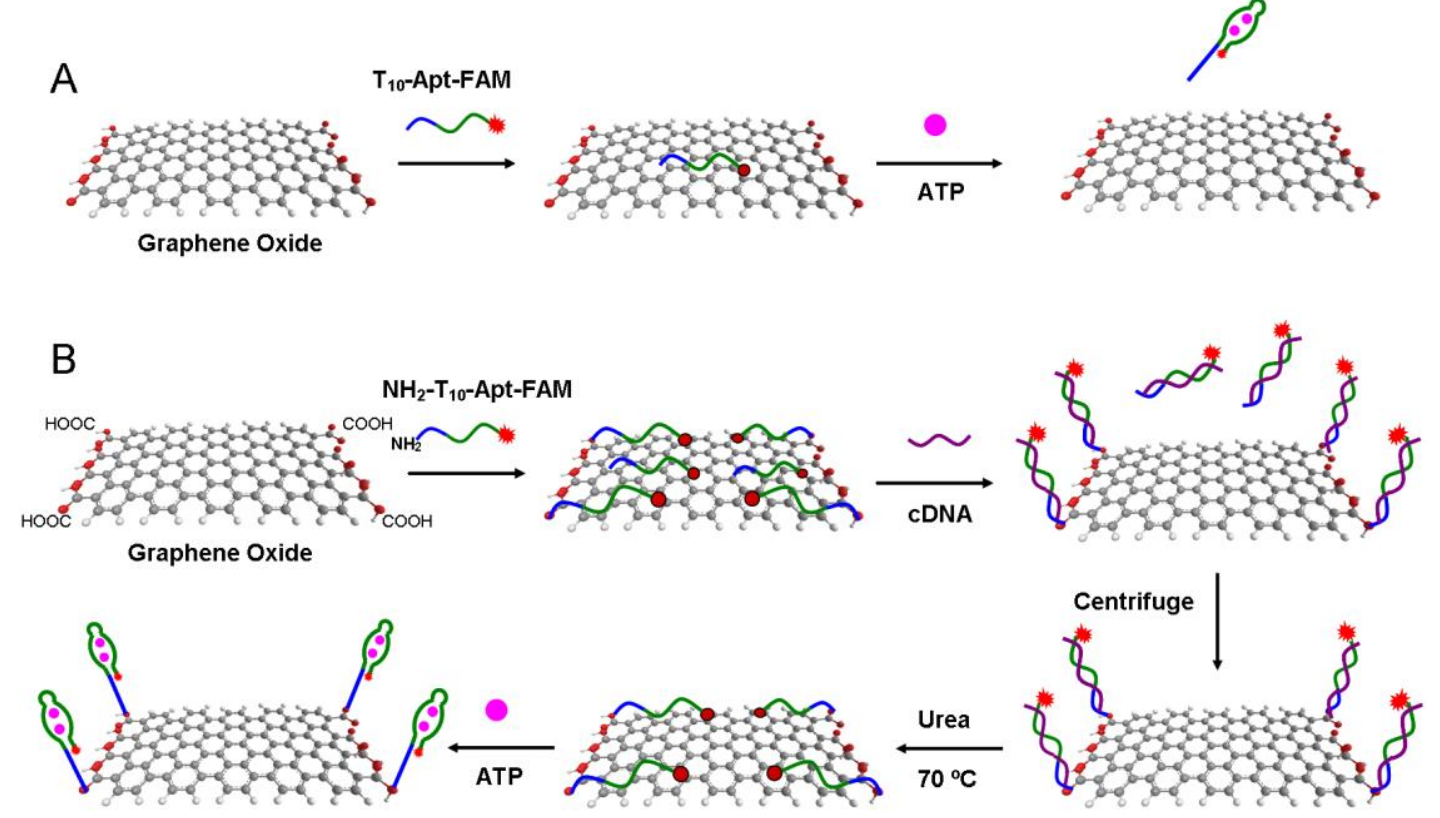

Figure 1. Schematic diagram of the sensing principle. A) Physisorption of the aptamer probe by GO for ATP detection. When adsorbed, the fluorescence is quenched. In the presence of ATP, the aptamer is released from the surface, leading to fluorescence enhancement. B) Covalent attachment of the aptamer probe to GO by forming an amide linkage. The physisorbed aptamers are removed by adding cDNA and the hybridized cDNA on GO are removed by urea and heating. This covalent beacon lights up on the GO surface by ATP and is less affected by non-specific displacement.

\section{Materials and Methods}

Chemicals. All the DNA samples were purchased from Integrated DNA Technologies, Inc. (IDT, Coralville, IA). The sequences and modifications of DNA are in Table 1. Carboxyl GO was form ACS Material (Medford, MA). EDC $\cdot \mathrm{HCl}$, adenosine triphosphate (ATP), uridine triphosphate (UTP), cytidine triphosphate (CTP) and MTT reagent were 
form Sigma-Aldrich (St. Louis, MO). NHS-Sulfate, Tris $\cdot \mathrm{HCl}, \mathrm{CaCl}_{2}$, urea, dimethyl sulfoxide and phosphate buffered saline (PBS) were from Sinopharm Chemical Reagent Co., Ltd. (Beijing, China). SMMC-7720 cells were provided by the Third Xiangya Hospital (Central South University, China). BSA was from Hao Yang biological manufacture Co., Ltd. (Tianjin, China). DMEM and RPMI 1640 medium were from HyClone (Logan, Utah, USA).

Sensor preparation. GO $(5 \mathrm{~mL}, 10 \mathrm{mg} / \mathrm{mL})$ was dispersed in water with ultrasonication for $15 \mathrm{~min}$ at $40 \mathrm{~W}$. The pulse was on for $2 \mathrm{sec}$ and then off for $2 \mathrm{sec}$. For the covalent sensor, the coupling reaction was carried out with $100 \mu \mathrm{L}$ of the above GO solution, to which MES (125 mM, pH 6.0), EDC (250 mM), and NHS-sulfate (250 mM) and amino-modified aptamer $(20 \mu \mathrm{M}, 50 \mu \mathrm{L})$ were added. Then water was added to give a final volume of $500 \mu \mathrm{L}$. The mixture was stirred at room temperature for $3 \mathrm{~h}$ in dark. The sample was centrifuged at $13500 \mathrm{rpm}$ for $15 \mathrm{~min}$ and washed with water. To remove physisorbed probe, $4 \mu \mathrm{M}$ cDNA1 or cDNA2 was added in buffer A ( $25 \mathrm{mM}$ HEPES, pH 7.6, $100 \mathrm{mM} \mathrm{Na}{ }^{+}, 1 \mathrm{mM} \mathrm{Mg}{ }^{2+}$ ). After $1 \mathrm{~h}$ incubation, the sample was centrifuged and washed. To remove the cDNA, the sample was soaked in $12 \mathrm{M}$ urea and heated at $70{ }^{\circ} \mathrm{C}$ for 10 min twice. Finally, the sample was washed by water, dispersed in Buffer A and stored at $4{ }^{\circ} \mathrm{C}$. To calculate the coupling efficiency, the fluorescence intensity of the supernatant of each washing step was measured in $\mathrm{pH} 8.5$ Tris buffer $(15 \mathrm{mM})$ and the fluorescence was compared against a standard curve. Fluorescence was measured with a microplate reader (Tecan Infinite $\mathrm{M} 200, \lambda_{\mathrm{ex}}=485 \mathrm{~nm}, \lambda_{\mathrm{em}}=520 \mathrm{~nm}$ ). To prepare the physisorbed sensor, $\mathrm{T}_{10}$-Apt-FAM $(500 \mathrm{nM})$ and $\mathrm{GO}(500 \mu \mathrm{g} / \mathrm{mL})$ were mixed in buffer A 
for $30 \mathrm{~min}$ at room temperature.

Sensor response. For both sensors, ATP at various concentrations was respectively incubated $(500 \mu \mathrm{g} / \mathrm{mL} \mathrm{GO})$ in buffer $\mathrm{A}$ at room temperature for $1 \mathrm{~h}$ before measurement. To measure specificity, $1 \mathrm{mM}$ ATP, UTP, or CTP was added. Similarly, BSA of 0.5, 1, 2, and $5 \mathrm{mg} / \mathrm{mL}$ was added to the two sensors and incubated for $1 \mathrm{~h}$ before fluorescence measurement.

Intracellular imaging. The SMMC-7720 cells were incubated with the sensors (GO concentration $=250 \mu \mathrm{g} / \mathrm{mL}$ ) for $8 \mathrm{~h}$. Cells without GO treatment were set as negative control. After incubation, the cells were washed with PBS for three times, and imaged with an inverted fluorescence microscope (Olympus IX-71). To stimulate ATP production, a sample was treated with $\mathrm{Ca}^{2+}(5 \mathrm{mM})$ for $2 \mathrm{~h} .{ }^{40}$ Then, the cells were incubated with the covalent sensor for $8 \mathrm{~h}$ before analysis.

Flow cytometry. The SMMC-7720 cells at a density of $1.5 \times 10^{4}$ cells/well were seeded in a 6-well microplate and incubated with the sensors for $8 \mathrm{~h}$. Then, the cells were treated with trypsin $(100 \mu \mathrm{L} /$ well $)$ for $1-2$ min at $37{ }^{\circ} \mathrm{C}$ and $500 \mu \mathrm{L}$ complete medium was added. The cells were collected after centrifugation at $800 \mathrm{rpm}$ for $4 \mathrm{~min}$, washed with PBS three times and suspended in $200 \mu \mathrm{L}$ PBS for analysis by flow cytometry (BD FACSCalibur). All the experiments were performed in triplicate and data were indicated as mean \pm SD. Statistical analysis was carried out according to the Student's t-test and one-way ANOVA analysis. $P<0.05$ was used as significant. 
Table 1. Sequences of the DNA used in this work

\begin{tabular}{|c|c|}
\hline Name & Sequence (from $5^{\prime}$ to $3^{\prime}$ ) \\
\hline $\mathrm{T}_{10}$-Apt1-FAM & FAM-ACC TGG GGG AGT ATT GCG GAG GAA GGT $\mathrm{T}_{10}$ \\
\hline $\mathrm{NH}_{2}$-Apt1-FAM & FAM-ACC TGG GGG AGT ATT GCG GAG GAA GGT-NH ${ }_{2}$ \\
\hline $\mathrm{NH}_{2}-\mathrm{T}_{10}-\mathrm{Apt} 1-\mathrm{FAM}$ & FAM-ACC TGG GGG AGT ATT GCG GAG GAA GGT T $\mathrm{T}_{10}-\mathrm{NH}_{2}$ \\
\hline $\mathrm{NH}_{2}-\mathrm{T}_{10}-\mathrm{Apt} 2-\mathrm{FAM}$ & FAM-ACC TGG GGG AGT A스 GCG GAG $\underline{\text { CAA GGT T }} 10-\mathrm{NH}_{2}$ \\
\hline cDNA1 & ACC TTC CTC CGC AAT ACT CCC CCA GGT \\
\hline cDNA2 & $\mathrm{A}_{10}$ ACC TTC CTC CGC AAT ACT CCC CCA GGT \\
\hline cDNA3 & $\mathrm{A}_{10}$ ACC TTG CTC CGC ATT ACT CCC CCA GGT \\
\hline
\end{tabular}

Note: Atp1 is the normal aptamer and Apt2 is a control sequence that cannot bind ATP. Mutated nucleotides are indicated by the underlines.

\section{Results and Discussion}

Covalent aptamer beacon. To facilitate cellular uptake, our GO sample was broken into nanoscale pieces by high power sonication. From AFM and TEM, they dispersed as single-layered sheets of 100-200 nm (Figure S1A, B, Supporting Information). XPS spectroscopy indicates an oxygen level of $32 \%$ (Figure S1C, D), and the level of carboxyl group is $\sim 6.3 \%$. Under optimized conditions, the sheets maintained excellent size stability ( 130 nm from dynamic light scattering) with zeta-potential of around $-30 \mathrm{mV}$ over 15 days (Figure S2). We used $500 \mu \mathrm{g} / \mathrm{mL}$ of GO for most of our experiments since it can completely and quickly adsorb $500 \mathrm{nM}$ of our aptamer probe (Figure S3).

To avoid non-specific displacement of the aptamer probe by non-target molecules, a covalent linkage was established using an amino and FAM (carboxyfluorescein) dual 
labelled ATP aptamer to react with the carboxyl group on GO in the presence of EDC. After the reaction, the IR peak at $1731 \mathrm{~cm}^{-1}(\mathrm{C}=\mathrm{O})$ disappeared, while a new peak appeared at $1653 \mathrm{~cm}^{-1}(\mathrm{C}=\mathrm{O}$, amide), suggesting formation of the amide bond (Figure $\mathrm{S} 4$ ). The covalent probe only undergoes a conformational change upon target binding without completely leaving the surface (Figure 1B).

Since the coupling efficiency is unlikely to be $100 \%$, in addition to those covalently attached, a fraction of the probes are physisorbed. These adsorbed aptamers need to be removed to obtain a pure covalent sensor. To achieve efficient probe removal, we first added the cDNA of the aptamer to form duplex (Figure 1B), which is known to desorb physisorbed probes. ${ }^{5,18,44}$ We optimized the salt concentration and incubation time of this hybridization reaction (Figure S5) and the optimal cDNA concentration was determined to be $4 \mu \mathrm{M}$ (Figure $2 \mathrm{~A}$ ). However, the covalently attached probes can also react with the cDNA and these cDNA needs to be removed as well to obtain functional sensors. Figure 2B shows that when fully hybridized with cDNA, the covalent sensor has a fluorescence intensity of $\sim 4000$ unit. Under this condition, all the covalently attached FAM-labeled probe DNAs are in an upright conformation. After heating the sample to $70{ }^{\circ} \mathrm{C}$ or with 12 M urea treatment, a fraction of the cDNA was removed, yielding a reading of $\sim 1400$ fluorescence unit due to the remaining cDNA. Optimization of the urea concentration is shown in Figure S6. ${ }^{47}$ The most efficient cDNA removal was achieved by combining urea and heating, after which the remaining fluorescence dropped to the background level. At this point, all the probes were free of the cDNA and they lie flat on the GO surface. Therefore, their fluorescence was quenched by GO, yielding a sensor ready for use. 
Coupling efficiency. Coupling efficiency is defined to be the fraction of aptamer attached compared to the total aptamer added. With a FAM label, we traced the fate of the aptamer probe at each step of treatment. After the EDC coupling reaction, all the probes were adsorbed (either chemically or physically), since no fluorescence was observed after washing the sample with water (the first bar in Figure 2C). After the cDNA treatment, $37.6 \%$ of the added aptamer was removed. Further treatment with urea and then heating in the presence of urea removed an additional $6.9 \%$ and $5.1 \%$, respectively. Urea not only denatures duplex DNA but also reduces the hydrogen bonding between DNA and GO. ${ }^{47}$ Finally, the remaining 50\% was covalently attached (the coupling efficiency was $\sim 50 \%$ ). Effect of spacer. Most aptamers give decreased end-to-end distance upon target binding, which makes it challenging to design a covalent sensor on GO. In the initial state of this ATP sensor, one end is covalently linked to GO, and the other end bearing FAM is likely to be physisorbed by GO. After binding to ATP, the FAM bearing end is still close to GO due to the way this aptamer folds. Indeed, little fluorescence enhancement was observed upon adding ATP when $\mathrm{NH}_{2}$-Apt1-FAM was used (Figure 2D, see Table 1 for DNA sequence). On the other hand, the signal increased by $\sim 25$-fold with the cDNA. Since GO quenches fluorescence in a distance-dependent manner, to achieve effective fluorescence recovery, we propose to introduce a spacer. With a $\mathrm{T}_{10}$ spacer (e.g. $\mathrm{NH}_{2}-\mathrm{T}_{10}-\mathrm{Apt} 1-\mathrm{FAM}$ with ten thymines), a strong signal was achieved upon adding ATP (although still weaker than adding the cDNA). We used a poly-thymine spacer because thymine has the weakest affinity with $\mathrm{GO},{ }^{48}$ and the electrostatic repulsion with the DNA backbone phosphate can point the DNA away from the surface of GO to achieve a large fluorescence increase. 

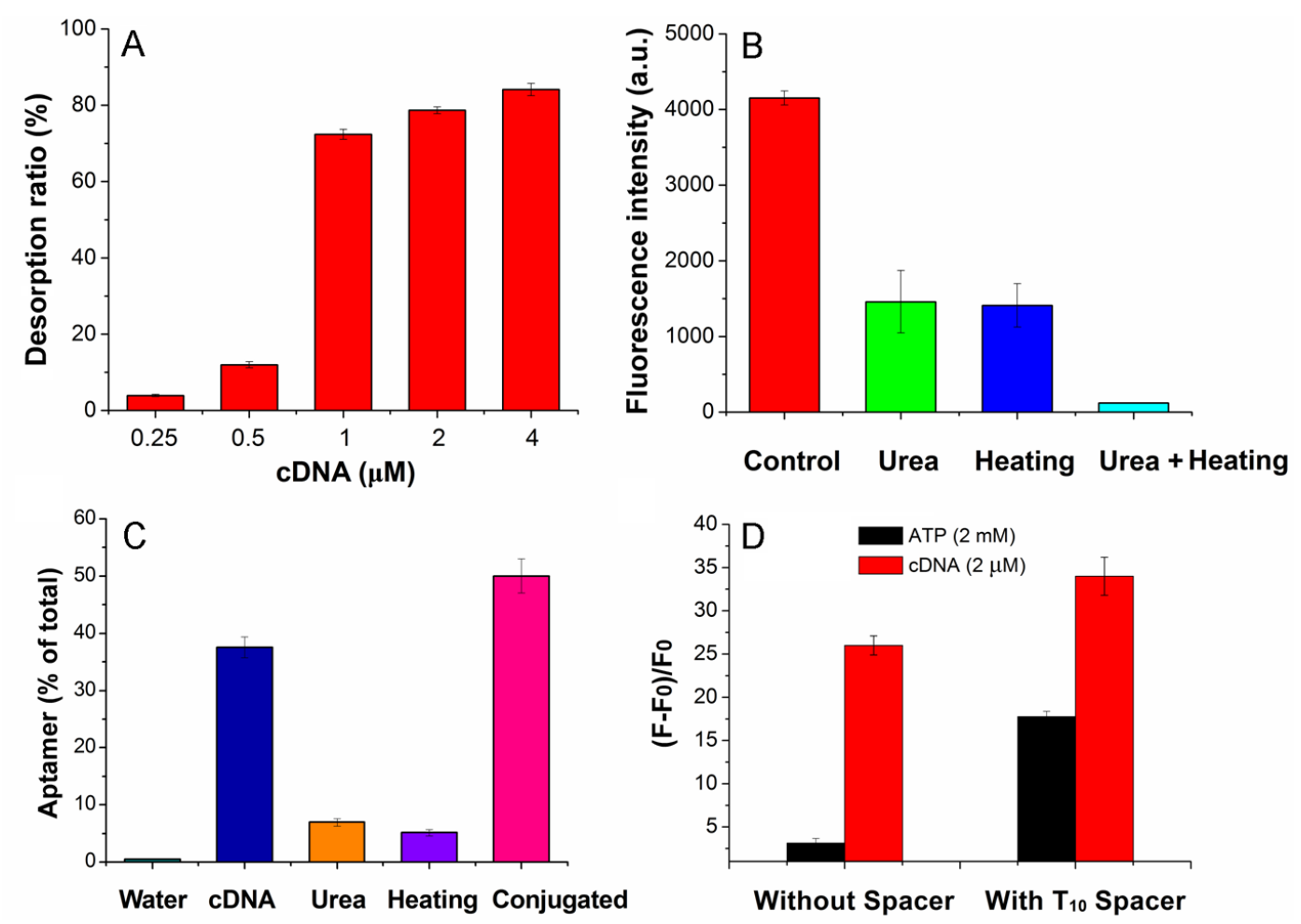

Figure 2. (A) Desorption ratio (the percentage of desorbed probe after adding cDNA compared to the initially adsorbed probe) of the physisorbed ATP aptamer as a function of cDNA concentration. (B) Optimization of cDNA removal conditions. Starting with the covalently labeled ATP aptamer probe after the cDNA treatment (control), the sample was further treated with $12 \mathrm{M}$ urea, or heating at $70{ }^{\circ} \mathrm{C}$ or both together. The fluorescence on the GO surface after each step of treatment was measured. Decreased fluorescence is due to probe flexibility after cDNA removal and quenching by GO (not permanent loss of the probe). (C) The percentage of aptamer loss after each washing step after the EDC coupling reaction, and the last bar is the covalently conjugated aptamer finally remained. The removed DNAs in the first four steps are physisorbed. (D) The fluorescence response of the covalent sensor without spacer or with a $\mathrm{T}_{10}$ spacer to ATP and cDNA. 
Detection in buffer. After preparing the covalent sensor, we first studied its performance in buffer in comparison with the physisorbed sensor. We chose $1 \mathrm{~h}$ for the detection time to achieve a stable signal (Figure S7A). For the covalent sensor, increased fluorescence was observed with increasing ATP concentration and the signal peaked at $2 \mathrm{mM}$ ATP (Figure 3A). The initial linear response has a slope of 8.02 fold enhancement per mM ATP from $0.125 \mathrm{mM}$ to $2 \mathrm{mM}$ ATP. The non-covalent sensor has a slope of 10.87 (Figure 3B). Since the analytical meaning of the slope is sensitivity, these two systems are similarly sensitive. This is reasonable since the same aptamer was used. On the other hand, the amount of fluorescence increase in the non-covalent sensor is twice of that in the covalent sensor, since the former allows a much larger distance change. The detection limit was $0.019 \mathrm{mM}$ ATP for the covalent sensor and $0.028 \mathrm{mM}$ for the non-covalent one based on signal greater than three times of background variation. Since the sensitivities of the two sensors are comparable, the slightly better detection limit for the covalent sensor is attributed to its lower background variation.

Next the selectivity was measured. Figure 3C, D indicate that both sensors have the highest response to ATP. The response of the covalent sensor to UTP or CTP is only $\sim 0.5$-fold, which is consistent with the high specificity of this aptamer. ${ }^{49}$ For the non-covalent sensor, however, UTP and CTP still produced 4-6 fold signal increase. This highlights an important advantage of the latter: better specificity. As a further control, a mutated aptamer (Apt2) was prepared. In both sensors, the response was quite low (the last bar in Figure 4C, D). Next, we measured the sensor response to BSA (Figure 3E), which was chosen to represent cellular proteins. Again, the covalent sensor has little 
response, while the fluorescence of the physisorbed sensor increased significantly. From all these comparisons, the covalent sensor is much more stable and less susceptible to non-target molecules. Finally, we regenerated the covalent sensor (Figure 3F) and it maintained a similar response in three test cycles. While for intracellular detection, the $\mathrm{pH}$ and salt concentrations are fixed by the cellular physiological conditions, we still explored these buffer conditions (Figure S7B, C). The sensor response is suppressed at low $\mathrm{pH}$ or with very high salt. Since under these conditions, the affinity between the aptamer and GO is too strong. ${ }^{19,50}$ Finally, the time-dependent sensor signal was followed and the signal was stable over a week (Figure S8). 

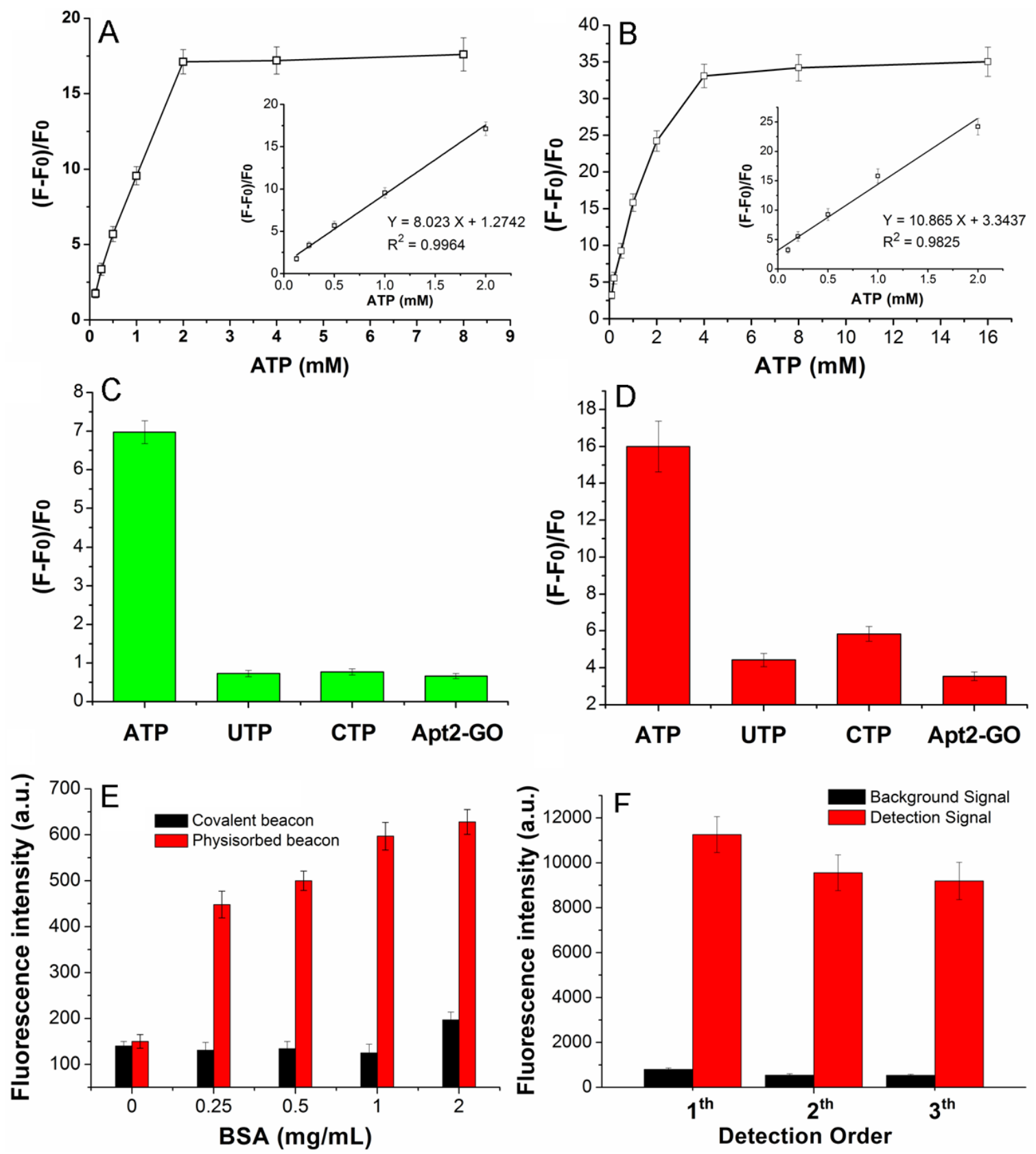

Figure 3. (A) Covalent and (B) physisorbed sensor response to various concentrations of ATP. The insets are the initial linear responses. $F$ and $F_{0}$ are the fluorescence intensity with or without ATP, respectively. The response of (C) the covalent sensor and (D) physisorbed sensor to $1 \mathrm{mM}$ ATP, UTP or CTP. Sensors prepared by a control aptamer $\left(\mathrm{NH}_{2}-\mathrm{T}_{10}-\mathrm{Apt} 2-\mathrm{FAM}\right)$ were included as controls. (E) Sensor response to BSA. (F) Response of the freshly prepared and regenerated covalent sensor with 0 or $2 \mathrm{mM}$ ATP. 
Intracellular detection. Next, we aim to apply this covalent probe for intracellular detection. This ATP aptamer is also known to bind many other adenine derivatives such as adenosine, AMP, and cAMP. ${ }^{49}$ Interestingly, a few independent work has indicated the feasibility of correlating the aptamer response to intracellular ATP concentration. ${ }^{38-41,51}$ For example, Mirkin and co-workers designed a gold nanoparticle/aptamer conjugate. In that work, they measured ATP concentration with a commercial ATP detection kit, which showed the same response as the aptamer sensor. ${ }^{51}$ Based on these previous reports, we also tested our sensor in cells.

SMMC-7720 cells were chosen for intracellular ATP detection. The GO sensor concentration was first optimized to be $250 \mu \mathrm{g} / \mathrm{mL}$ to achieve an optimal signal (Figure S9). The optimal incubation time was $8 \mathrm{~h}$ (Figure S10). The cells maintained their viability under this condition and the DNA was also protected by GO from nuclease degradation (Figure S11). Each sample was analyzed by both fluorescence microscopy and flow cytometry. The untreated cells were non-fluorescent as expected (Figure 4A). With the physisorbed sensor (Figure 4B), weak fluorescence signal was observed, which is attributed to the loss of probe DNA by non-specific displacement before the sensor reaching the cells (Figure S12). Figure 4C shows strong fluorescence from the covalent sensor. Note that in the clean buffer, the response of the non-covalent sensor was doubled compared to the covalent sensor (Figure 3A, B). Therefore, the initial probe density of the non-covalent sensor is likely to be higher. The fact that the intracellular signal is much stronger for the covalent sensor further supports the importance of suppressing non-specific probe release. Next we prepared another covalent sensor using the control 
aptamer, which cannot bind ATP (Figure 4D). In this case, the response was fairly weak, which confirms that the signal in Figure 4C was indeed from the specific ATP binding.

Finally, to test whether this covalent probe can monitor the variation of ATP concentration, we stimulated the cells by $\mathrm{Ca}^{2+}$ (Figure 4E), which was reported to increase the intracellular ATP level. ${ }^{40,52}$ For quantification, we also performed flow cytometry analysis (Figure S13) and the average fluorescence is shown in Figure 5. After $\mathrm{Ca}^{2+}$ treatment, the fluorescence signal further enhanced by $\sim 32 \%$. This study indicates that the fluorescence signal of covalent beacons is positively related to the intracellular ATP concentration. 

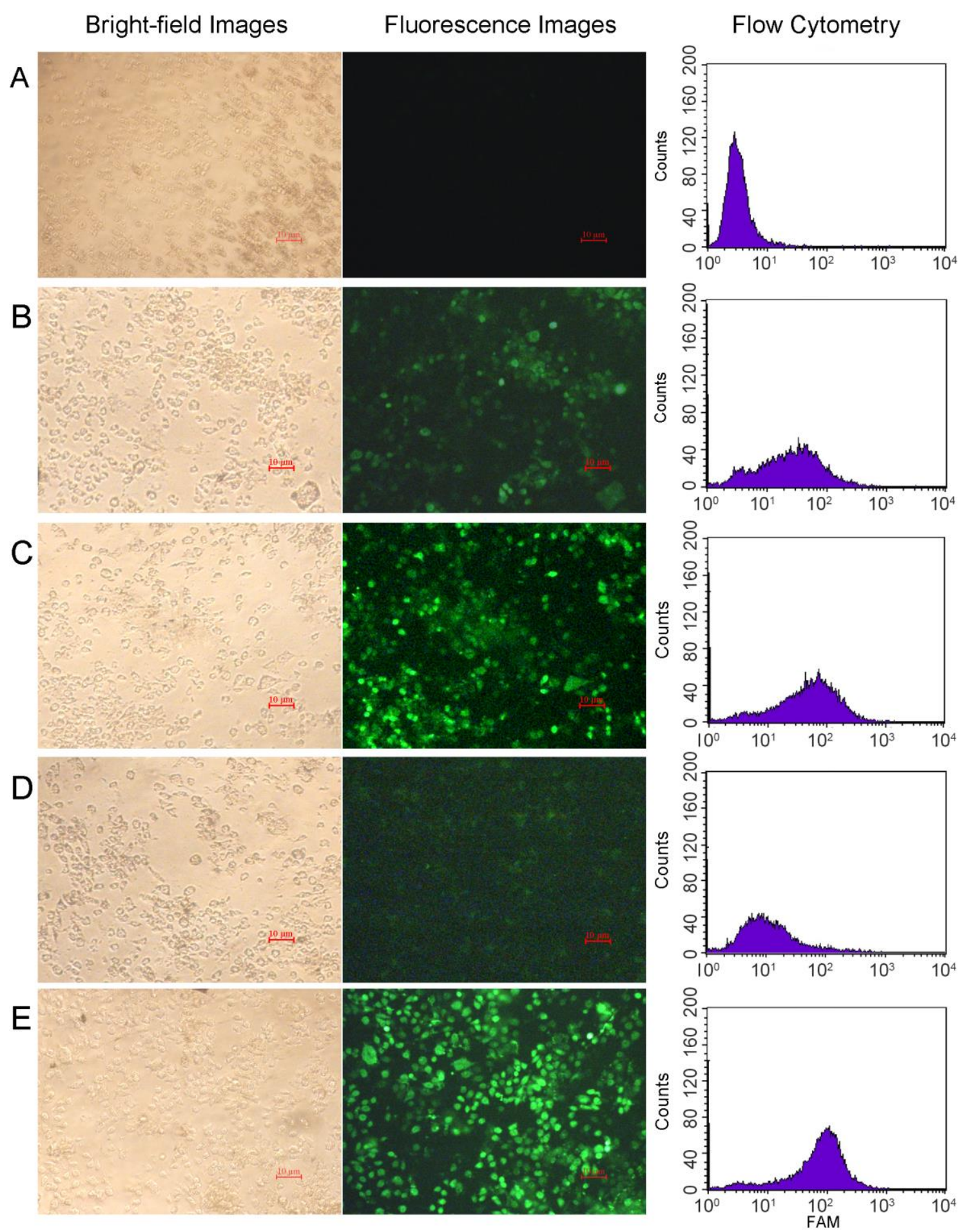

Figure 4. Microscopy and flow cytometry results of SMMC-7720 cells incubated with

(A) medium only; (B) physisorbed sensor ( $\mathrm{T}_{10}$-Apt1-FAM); (C) covalent sensor with $\mathrm{NH}_{2}-\mathrm{T}_{10}$-Apt1-FAM; or (D) covalent sensor but with the control aptamer $\left(\mathrm{NH}_{2}-\mathrm{T}_{10}-\mathrm{Apt} 2-\mathrm{FAM}\right)$ that cannot bind ATP. (E) The cells were treated with $\mathrm{Ca}^{2+}$ before 
the covalent sensor was added. For each figure, the left panel is bright field image, the middle one is the fluorescence image and the right one is the flow cytometry histogram. Scale bars $=10 \mu \mathrm{m}$.

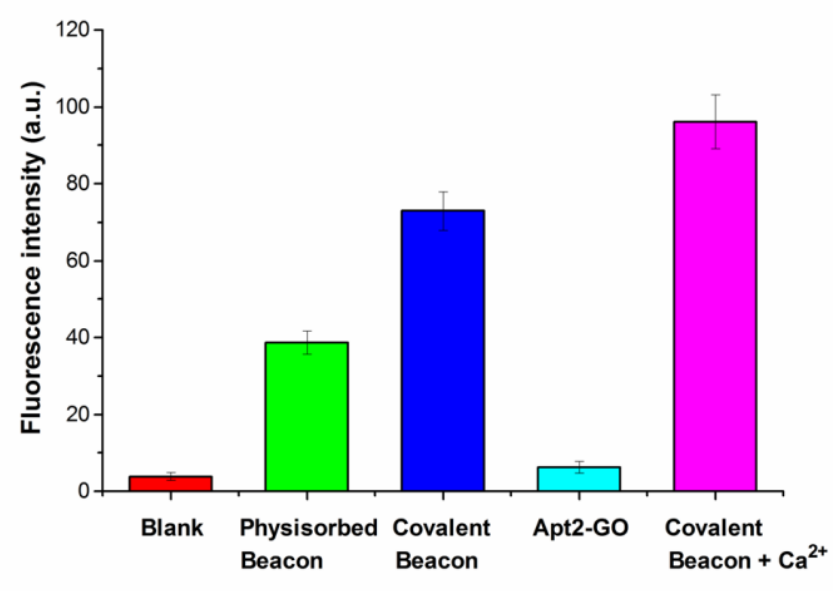

Figure 5. The fluorescence intensity of SMMC-7720 cells incubated with various sensors and controls measured by flow cytometry.

\section{CONCLUSIONS}

While intracellular detection using the GO-aptamer system has been reported in a few papers, this is the first example of covalent probe for ATP. All the previous assays involved only physisorbed aptamer probes. In this work, we performed a side-by-side comparison of these two systems. In pure buffer, the physisorbed probe has a much higher fluorescence signal, while for intracellular detection, its response is much lower. This result highlights the importance of covalent conjugation for detection in complex biological sample matrix. In these systems, many proteins, nucleic acids and even some small molecules might non-specifically displace adsorbed DNA probes. This method is 
not restricted to ATP detection. By covalently attaching other types of aptamers, we may achieve intracellular detection of multiple analytes.

\section{Supporting Information}

Additional methods, GO microscopy, zeta-potential, DNA desorption optimization, intracellular detection optimization. This material is available free of charge via the Internet at http://pubs.acs.org.

\section{Acknowledgements}

This work was supported by the National Natural Science Foundation of China (Grant No. 81301258, 21301195), the Hunan Provincial Natural Science Foundation of China (Grant No. 13JJ4029), the Specialized Research Fund for the Doctoral Program of Higher Education of China (Grant No. 20130162120078), the Postdoctoral Science Foundation of Central South University and China (Grant No. 124896), the China Postdoctoral Science Foundation (Grant No. 2013M540644), the International Postdoctoral Exchange Fellowship Program [2014]29 (Grant No. 20140014), the Shenghua Scholar Foundation, and the NSERC of Canada. 


\section{References:}

(1) Geim, A. K. Science 2009, 324, 1530-1534.

(2) Novoselov, K. S.; Falko, V. I.; Colombo, L.; Gellert, P. R.; Schwab, M. G.; Kim, K. Nature 2012, 490, 192-200.

(3) Schedin, F.; Geim, A. K.; Morozov, S. V.; Hill, E. W.; Blake, P.; Katsnelson, M. I.; Novoselov, K. S. Nat. Mater. 2007, 6, 652-655.

(4) Loh, K. P.; Bao, Q.; Eda, G.; Chhowalla, M. Nat Chem 2010, 2, 1015-1024.

(5) Lu, C. H.; Yang, H. H.; Zhu, C. L.; Chen, X.; Chen, G. N. Angew. Chem. Int. Ed. 2009, 48, 4785-4787.

(6) Liu, Z.; Liu, B.; Ding, J.; Liu, J. Anal. Bioanal. Chem. 2014, 406, 6885-6902.

(7) Chen, D.; Feng, H.; Li, J. Chem. Rev. 2012, 112, 6027-6053.

(8) Wang, Y.; Li, Z. H.; Wang, J.; Li, J. H.; Lin, Y. H. Trends Biotechnol. 2011, 29, $205-212$

(9) Li, D.; Song, S. P.; Fan, C. H. Acc. Chem. Res. 2010, 43, 631-641.

(10) Wang, H.; Yang, R. H.; Yang, L.; Tan, W. H. ACS Nano 2009, 3, 2451-2460.

(11) Cui, L.; Song, Y.; Ke, G.; Guan, Z.; Zhang, H.; Lin, Y.; Huang, Y.; Zhu, Z.; Yang, C. J. Chem. Eur. J 2013, 19, 10442-10451.

(12) Kim, J.; Cote, L. J.; Kim, F.; Huang, J. J. Am. Chem. Soc. 2010, 132, 260-267.

(13) He, S. J.; Song, B.; Li, D.; Zhu, C. F.; Qi, W. P.; Wen, Y. Q.; Wang, L. H.; Song, S. P.; Fang, H. P.; Fan, C. H. Adv. Funct. Mater. 2010, 20, 453-459.

(14) Huang, P.-J. J.; Liu, J. Small 2012, 8, 977-983.

(15) Zhao, X. H.; Kong, R. M.; Zhang, X. B.; Meng, H. M.; Liu, W. N.; Tan, W. H.; 
Shen, G. L.; Yu, R. Q. Anal. Chem. 2011, 83, 5062-5066.

(16) Zheng, M.; Jagota, A.; Semke, E. D.; Diner, B. A.; McLean, R. S.; Lustig, S. R.; Richardson, R. E.; Tassi, N. G. Nat. Mater. 2003, 2, 338-342.

(17) Wu, M.; Kempaiah, R.; Huang, P.-J. J.; Maheshwari, V.; Liu, J. Langmuir 2011, $27,2731-2738$.

(18) Tang, Z. W.; Wu, H.; Cort, J. R.; Buchko, G. W.; Zhang, Y. Y.; Shao, Y. Y.; Aksay, I. A.; Liu, J.; Lin, Y. H. Small 2010, 6, 1205-1209.

(19) Liu, B.; Sun, Z.; Zhang, X.; Liu, J. Anal. Chem. 2013, 85, 7987-7993.

(20) Tu, X.; Manohar, S.; Jagota, A.; Zheng, M. Nature 2009, 460, 250-253.

(21) Yang, R. H.; Jin, J. Y.; Chen, Y.; Shao, N.; Kang, H. Z.; Xiao, Z.; Tang, Z. W.; Wu, Y. R.; Zhu, Z.; Tan, W. H. J. Am. Chem. Soc. 2008, 130, 8351-8358.

(22) Jeng, E. S.; Moll, A. E.; Roy, A. C.; Gastala, J. B.; Strano, M. S. Nano Lett. 2006, 6, 371-375.

(23) Zhang, X.-B.; Kong, R.-M.; Lu, Y. Annu. Rev. Anal. Chem. 2011, 4, 105-128.

(24) Chang, H. X.; Tang, L. H.; Wang, Y.; Jiang, J. H.; Li, J. H. Anal. Chem. 2010, 82, 2341-2346.

(25) Liu, J.; Cao, Z.; Lu, Y. Chem. Rev. 2009, 109, 1948-1998.

(26) Song, S. P.; Wang, L. H.; Li, J.; Zhao, J. L.; Fan, C. H. Trac-Trend. Anal. Chem. 2008, 27, 108-117.

(27) Fang, X. H.; Tan, W. H. Acc. Chem. Res. 2010, 43, 48-57.

(28) He, Y.; Wang, Z. G.; Tang, H. W.; Pang, D. W. Biosens. Bioelectron. 2011, 29, $76-81$. 
(29) Gao, L.; Lian, C.; Zhou, Y.; Yan, L.; Li, Q.; Zhang, C.; Chen, L.; Chen, K. Biosens. Bioelectron. 2014, 60, 22-29.

(30) Wang, K. M.; Huang, J.; Yang, X. H.; He, X. X.; Liu, J. B. Analyst 2013, 138, $62-71$.

(31) He, Y.; Wang, Z.-G.; Tang, H.-W.; Pang, D.-W. Biosens. Bioelectron. 2011, 29, $76-81$.

(32) Hu, R.; Zhang, X.; Zhao, Z.; Zhu, G.; Chen, T.; Fu, T.; Tan, W. Angew. Chem., Int. Ed. 2014, 53, 5821-5826.

(33) Meng, H.-M.; Zhang, X.; Lv, Y.; Zhao, Z.; Wang, N.-N.; Fu, T.; Fan, H.; Liang, H.; Qiu, L.; Zhu, G.; Tan, W. ACS Nano 2014, 8, 6171-6181.

(34) Rosi, N. L.; Giljohann, D. A.; Thaxton, C. S.; Lytton-Jean, A. K. R.; Han, M. S.; Mirkin, C. A. Science 2006, 312, 1027-1030.

(35) Sun, X. M.; Liu, Z.; Welsher, K.; Robinson, J. T.; Goodwin, A.; Zaric, S.; Dai, H. J. Nano Research 2008, 1, 203-212.

(36) Yang, K.; Feng, L.; Shi, X.; Liu, Z. Chem. Soc. Rev. 2013, 42, 530-547.

(37) Lu, C. H.; Zhu, C. L.; Li, J.; Liu, J. J.; Chen, X.; Yang, H. H. Chem. Commun. 2010, 46, 3116-3118.

(38) Wang, Y.; Li, Z. H.; Hu, D. H.; Lin, C. T.; Li, J. H.; Lin, Y. H. J. Am. Chem. Soc. 2010, 132, 9274-9276.

(39) Wang, Y.; Li, Z. H.; Weber, T. J.; Hu, D. H.; Lin, C. T.; Li, J. H.; Lin, Y. H. Anal. Chem. 2013, 85, 6775-6782.

(40) Tan, X.; Chen, T.; Xiong, X.; Mao, Y.; Zhu, G.; Yasun, E.; Li, C.; Zhu, Z.; Tan, W. 
Anal. Chem. 2012, 84, 8622-8627.

(41) Yi, M.; Yang, S.; Peng, Z.; Liu, C.; Li, J.; Zhong, W.; Yang, R.; Tan, W. Anal. Chem. 2014, 86, 3548-3554.

(42) Wang, Y.; Tang, L. H.; Li, Z. H.; Lin, Y. H.; Li, J. H. Nat. Protoc. 2014, 9, 1944-1955.

(43) Wang, K. M.; Tang, Z. W.; Yang, C. Y. J.; Kim, Y. M.; Fang, X. H.; Li, W.; Wu, Y. R.; Medley, C. D.; Cao, Z. H.; Li, J.; Colon, P.; Lin, H.; Tan, W. H. Angew. Chem. Int. Ed. 2009, 48, 856-870.

(44) Huang, P.-J. J.; Liu, J. Anal. Chem. 2012, 84, 4192-4198.

(45) Mohanty, N.; Berry, V. Nano Lett. 2008, 8, 4469-4476.

(46) Gruenhagen, J. A.; Lovell, P.; Moroz, L. L.; Yeung, E. S. J. Neurosci. Methods 2004, 139, 145-152.

(47) Park, J. S.; Na, H.-K.; Min, D.-H.; Kim, D.-E. Analyst 2013, 138, 1745-1749.

(48) Antony, J.; Grimme, S. Phys. Chem. Chem. Phys. 2008, 10, 2722-2729.

(49) Huizenga, D. E.; Szostak, J. W. Biochemistry 1995, 34, 656-665.

(50) Huang, P.-J. J.; Kempaiah, R.; Liu, J. J. Mater. Chem. 2011, 21, 8991-8993.

(51) Zheng, D.; Seferos, D. S.; Giljohann, D. A.; Patel, P. C.; Mirkin, C. A. Nano Lett. 2009, 9, 3258-3261.

(52) Zamaraeva, M. V.; Sabirov, R. Z.; Maeno, E.; Ando-Akatsuka, Y.; Bessonova, S. V.; Okada, Y. Cell Death Differ. 2005, 12, 1390-1397. 